\title{
Leituras para (re)pensar o trabalho coletivo dos professores de Educação Física ${ }^{1}$
}

\author{
Fabiano Bossle*
}

Vicente Molina Neto**

\begin{abstract}
Resumo: Este artigo é uma revisão bibliográfica sobre o trabaIho coletivo na educação física escolar brasileira. O objetivo é revisar, nas produções da Área de Conhecimento da Educação Física e Ciências do Esporte, as abordagens sobre o trabalho coletivo. Foram analisados os anais de três congressos da área de conhecimento da educação física e ciências do esporte nos anos de 2006 e 2007, livros e teses e dissertações. Foi possível identificar o contexto em que emerge as discussões sobre trabalho coletivo na educação física escolar brasileira e o espaço que esta temática tem ocupado na produção desta Área de Conhecimento, nos dias de hoje, bem como uma "simbiose" entre trabalho coletivo na educação física e propostas político-pedagógicas fundamentadas na horizontalização das relações na escola.
\end{abstract}

Palavras-chave: Literatura de revisão como assunto. Docentes. Educação Física escolar.

\section{INTRODUÇÃO}

Para delimitar o foco desta investigação, realizaremos uma revisão bibliográfica sobre trabalho coletivo na área de conhecimento da educação física que possibilitasse retomar alguns aspectos já destacados na literatura e construir caminhos teóricos para a investigação. Desta forma, nosso objetivo com este texto é revisar, nas

\footnotetext{
1 Artigo resultante da dissertação do autor: Planejamento de Ensino dos Professores de Educação Física do $2^{\circ}$ e $3^{\circ}$ Ciclos da Rede Municipal de Ensino de Porto Alegre: um estudo do tipo etnográfico em quatro escolas desta Rede de Ensino. Porto Alegre: UFRGS, 2003 * Professor assistente do Centro Universitário Univates. Professor da Faculdade Cenecista de Osório. Professor de educação física da Rede Municipal de Ensino de Porto Alegre. Porto Alegre, RS, Brasil. E-mail: c.bossle@terra.com.br

** Professor de Graduação e Pós-Graduação da ESEF da Universidade Federal do Rio Grande do Sul (UFRGS). Porto Alegre, RS, Brasil. E-mail: vicente.neto@ufrgs.br
} 


\section{Artigos Orifinais Fabiano Bossle, Vicente Molina Neto}

produções da Educação Física e Ciências do Esporte, as abordagens sobre o trabalho coletivo.

Para situar nossa perspectiva de análise, destacamos a inquietação para investigar o trabalho coletivo dos professores de educação física. Esta inquietação emergiu na realização de uma investigação anterior (BOSSLE, 2003) em que percebemos a existência de práticas educativas construídas de maneira isolada por este coletivo docente. Sublinhamos que esta temática assume significativa importância, porque nossas investigações focalizam, sobretudo, os significados que esses professores têm atribuído às suas práticas educativas nas escolas que organizam o ensino em ciclos de formação, como é o caso da Rede Municipal de Ensino de Porto Alegre.

O ensino organizado por ciclos de formação está centrado em alguns pressupostos, entre os quais o que sublinha que o trabalho coletivo é fundamental para a aprendizagem (PORTO ALEGRE, 1999). O trabalho coletivo adquire esta condição de centralidade na Proposta Político-Pedagógica desta Rede de Ensino na medida em que o ensino organizado por ciclos de formação pressupõe a horizontalização das relações que são estabelecidas pelas comunidades escolares (equipe diretiva, professores, pais, estudantes e funcionários). Desse modo, o processo de ensino-aprendizagem estaria pautado na interação entre os diferentes atores sociais e o objeto de conhecimento que emerge nos contextos singulares de escolarização e é ressignificado de maneira coletiva.

Foi nesta perspectiva que o trabalho coletivo nos inquietou. De maneira mais específica, investigar o trabalho coletivo pensado e construído pelos professores de educação física da Rede Municipal de Ensino de Porto Alegre diante do ensino organizado por ciclos de formação. A partir desta delimitação, iniciamos uma revisão bibliográfica, tendo como descritores: educação física escolar e trabalho coletivo.

\section{Trabalho coletivo e educação física escolar}

Iniciamos o movimento de revisão bibliográfica com a análise sobre o trabalho coletivo dos professores de educação física em três

Movimento, Porto Alegre, v. 15, n. 03, p. 89-107, julho/setembro de 2009. 
versões recentes de congressos que mobilizaram um número significativo de pesquisadores da área de conhecimento em foco nos anos de 2006 e 2007. Assim, analisamos os trabalhos apresentados em anais dos seguintes eventos:

21. Congresso Internacional de Educação Física (FIEP) de 2006; do 11. Congresso de Ciências do Desporto e Educação Física dos Países de Língua Portuguesa (CCDEF) de 2006 e do 15. Congresso Brasileiro de Ciências do Esporte (CONBRACE) de 2007.

Tabela 1: Trabalhos apresentados nos três eventos da área de educação física.

\begin{tabular}{l|c|c|c|c}
\hline Congressos & $\begin{array}{c}\text { Trabalhos } \\
\text { apresentados }\end{array}$ & $\begin{array}{c}\text { Trabalhos em } \\
\text { EFI Escolar }\end{array}$ & $\begin{array}{c}\text { Trabalhos em que } \\
\text { o trabalho docente } \\
\text { coletivo foi o tema } \\
\text { principal }\end{array}$ & $\begin{array}{c}\text { Trabalhos em que } \\
\text { o trabalho docente } \\
\text { coletivo emergiu } \\
\text { de maneira } \\
\text { secundária }\end{array}$ \\
\hline FIEP & 166 & 21 & 0 & 0 \\
\hline CCDEF & 1051 & 112 & 0 & 04 \\
\hline CONBRACE & 362 & 40 & 0 & 04 \\
\hline TOTAL & 1579 & 173 & 0 & 08 \\
\hline
\end{tabular}

É possível perceber, nos dados apresentados na Tabela 1, que, embora haja um número significativo de trabalhos enviados aos três congressos de educação física, ainda há pouca produção científica sobre o trabalho docente coletivo nesta área de conhecimento. Essa análise permitiu identificar, ainda, que o trabalho coletivo na educação física escolar não foi tema principal em nenhum trabalho apresentado, mas emergiu de maneira secundária no interior de outras análises e discussões. Assim, podemos interpretar que apesar de emergir em algumas análises e interpretações sobre a educação física escolar de maneira secundária, este tema ainda não tenha inquietado suficientemente os pesquisadores desta área de conhecimento a ponto de haver uma produção significativa que o coloque como temática central.

O que emergiu nos oito trabalhos encontrados não foi a expressão "trabalho coletivo", mas a interpretação sobre práticas educativas e possibilidades de aproximação coletivas ou de colaboração em contextos específicos. Nesse sentido, Pedroza e Rodrigues (2007) interpretaram, entre outros aspectos, que há uma contradição entre a proposta

Movimento, Porto Alegre, v. 15, n. 03, p. 89-107, julho/setembro de 2009. 


\section{Antigos Orifinais Fabiano Bossle, Vicente Molina Neto}

de ciclos de desenvolvimento humano que é construída em uma escola da Rede Municipal de Goiânia/Goiás, e um "debate coletivo" previsto nesta e que não ocorreu. Este "debate coletivo" a que se referem esses autores estaria pautado na perspectiva de uma participação da comunidade escolar na avaliação do processo de ensinoaprendizagem nas aulas de educação física.

A partir da leitura do texto de Diehl, Günther e Lourenço (2007), foi possível perceber uma interpretação oposta à apresentada anteriormente por Pedroza e Rodrigues (2007). Identificaram, no estudo que realizaram nas escolas da Rede Municipal de Ensino de Porto Alegre, a existência de algumas iniciativas que apontam para a renovação e democratização do trabalho pedagógico, sendo que o redimensionamento das ações pedagógicas é percebido como um caminho para a construção da autonomia e de um processo coletivo que promova mudanças institucionais e sociais do ensino.

Reforçando este pensamento apresentado por Diehl, Günther e Lourenço (2007), Merida (2006) enfatiza esta possibilidade de aproximação entre os professores na construção de mudanças a partir da realização do planejamento anual. Destacou, também, a construção coletiva do planejamento anual como uma possibilidade de refletir e discutir para além de suas disciplinas, percebendo, desse modo, a "totalidade" do processo de aprendizagem que é desenvolvido em uma escola de São Paulo. Estes achados também são convergentes com os apresentados por Oliveira e Oliveira (2006) sobre a aproximação entre as práticas educativas construídas pelos professores $\mathrm{e}$ as disciplinas que lecionam de maneira "integrada" e na crítica apresentada por Schmidt et al (2006) com relação à ausência de uma "unidade de ação".

A ação pedagógica desenvolvida pelos professores de educação física e a construção do sujeito coletivo e da identidade coletiva emergem nos trabalhos de Silva e Molina Neto (2006), Silva e Sanchotene (2007) e Figueiredo e colaboradoras (2007). Destacamos a convergência nos dois trabalhos apresentados de um caráter processual de construção de identidades coletivas, na medida em que há reconhecimento das próprias práticas educativas, ou seja, da subjetividade

Movimento, Porto Alegre, v. 15, n. 03, p. 89-107, julho/setembro de 2009. 
e reconhecimento de cada professor de educação física sobre o entendimento do que é ser professor.

Essa revisão bibliográfica permitiu construir um diálogo entre os autores. Embora o trabalho docente coletivo seja um pressuposto teórico de muitas Propostas Político-Pedagógicas de diferentes redes de ensino pelo Brasil, sua abordagem não tem surgido de maneira central em pesquisas da área de conhecimento da educação física e ciências do esporte. Porém, o trabalho coletivo tem sido tematizado no interior de interpretações sobre um conjunto de práticas construídas pelos professores de educação física nas escolas.

Ao refletir sobre a construção coletiva do fazer pedagógico, Neira (2004) advoga em favor da existência de um projeto com a participação dos diferentes segmentos da escola. Para este autor, o projeto coletivo, na medida em que envolve a todos em sua construção, seria uma forma de modificar o quadro atual de fragmentação e desarticulação, promovido, em parte, pelas condições de trabalho do magistério. Este reconhecimento das condições sociais de escolarização (LISTON; ZEICHNER, 1997) pode ser interpretado como um elemento de configuração interessante para a compreensão sobre o trabalho coletivo na educação física, como tem apontado os estudos do grupo de pesquisa qualitativa Formação de Professores e Prática Pedagógica na Educação Física e Ciências do Esporte (F3P-EFICE) de Günther (2000, 2006); Wittizorecki (2001); Bossle (2003), Santini (2004); Pereira (2004); Silva (2007); Santos (2007); Sanchotene (2007); Diehl (2007).

Neste sentido, o trabalho coletivo é vislumbrado em uma proposta de planejamento coletivo através dos autores Palafox (2002; 2004) e Terra (2003; 2004). A proposta desses autores, além da realização de uma proposta coletiva no interior de um processo de formação continuada para os professores de educação física da Rede Pública Municipal de Uberlândia/MG, que vem sendo desenvolvida desde 1993, foi a de resgatar e valorizar esta disciplina como componente curricular, através da abordagem crítica do planejamento de ensino.

Sublinhamos que é justamente em uma perspectiva crítica de educação física que encontramos movimentos que conduzem ao

Movimento, Porto Alegre, v. 15, n. 03, p. 89-107, julho/setembro de 2009. 


\section{Artigor Originais Fabiano Bossle, Vicente Molina Neto}

pensar a coletividade no trabalho docente na educação física escolar (KUNZ, 1991; BRACHT, 1992; SOARES, 1992; TAFFAREL, 1993). Conforme já foi constatado pela comunidade que investiga a história da educação física, nos anos 1980, ocorreu um movimento na educação física brasileira que marcou um posicionamento crítico de alguns autores em relação à prática educativa vigente. Neste sentido, são significativas as contribuições de Hildebrandt-Stramann e Laging (1986) e Hildebrandt-Stramann (2001) sobre as concepções abertas no ensino da educação física. Destacamos aqui, além da influência e da contribuição marcante destes autores na formação de muitos pesquisadores de relevância nacional e internacional nos anos $1980 \mathrm{e}$ início dos anos 1990, a defesa da tese da descentralização das decisões nas aulas de educação física já antecipa a organização do trabalho coletivo neste espaço/tempo.

Entendemos que a ideia de descentralização demarca uma ruptura com a prática centrada única e exclusivamente no professor de educação física e abre a possibilidade de construção de práticas coletivas. Desta forma, a concepção de aulas abertas demarca uma contraposição ao modelo de aulas que podem ser denominadas fechadas, em que as decisões ficavam centradas no professor e em seus interesses. Fato esse que corrobora com os achados de alguns estudos realizados neste período, como Kunz $(1991 ; 1994)$ e Molina Neto (1993). Assim, Hildebrandt-Stramann (2001, p. 141) sublinha que a concepção de aulas fechadas toma por base as concepções do professor e estão centradas no produto, nas "[...] metas definidas e na intenção racionalista" do planejamento, dos conteúdos e da avaliação do processo de ensino-aprendizagem, enquanto que a concepção de aulas abertas é orientada no processo, na problematização e na comunicação entre os sujeitos e o entorno. A concepção de aulas abertas parte, basicamente, da premissa de que a experiência dos estudantes é significativa para a construção de uma aula de educação física, exigindo uma participação maior de todos e não centrada nos interesses e nas decisões do professor.

Sob o ponto de vista crítico de educação voltada para o desenvolvimento da capacidade de ação, a aula de Educação Física deve configurar-se como

Movimento, Porto Alegre, v. 15, n. 03, p. 89-107, julho/setembro de 2009. 
um sistema de ação aberto. Nesse tipo de aula é importante que os professores e os alunos se entendam sobre o sentido das ações e, ao mesmo tempo, sobre os objetivos, conteúdos e métodos de aula e do esporte (HILDEBRANDT-STRAMANN, 2001, p. 142).

Neste sentido, pensando que a aula de educação física pode ser construída de diferentes maneiras - entre elas a de concepção aberta, o Grupo de Trabalho Pedagógico da UFPE/UFSM (1991) sublinha que podem existir, também, diferentes consequências sociais para os participantes. Assim, a socialização e a interação assumem um caráter significativo na formação dos estudantes, na medida em que há compreensão de que somos seres sociais e da dimensão do próprio processo de individualização, de desenvolvimento de cada indivíduo como ser único e inconfundível - singular. Com este pensamento, o Grupo de Trabalho Pedagógico retoma, de maneira enfática, a ideia central de Hildebrandt-Stramann (2001) de que a prática educativa deve ser realizada considerando a experiência dos educandos e não somente a do professor, aproximando-se, dessa forma, da compreensão de Soares, (1992) sobre o entendimento de uma metodologia de ensino como forma de apreensão do conhecimento específico da educação física - a cultura corporal como linguagem social e historicamente construída.

Entendemos que este movimento que envolve a concepção de aulas abertas trouxe uma contribuição significativa ao pensar coletivo na educação física. Podemos pensar que a educação física tradicional (BRACHT, 1992; CASTELLANI FILHO, 1994) tinha em sua gênese a centralidade não só das decisões sobre o que fazer, mas, também, a condução de um processo didático-metodológico em que a aprendizagem estava amparada nas crenças e valores do professor. Deste modo, poderia não representar necessariamente a cultura (corporal) viva e dinâmica dos estudantes e da comunidade em seu entorno, identificando-se mais como reprodutora do que crítica (BRACHT, 1992), na medida em que não promove um diálogo entre os participantes da ação.

Este diálogo entre estudantes e professores de educação física é requerido também por Moreira (2004), Corrêa e Moro (2004),

Movimento, Porto Alegre, v. 15, n. 03, p. 89-107, julho/setembro de 2009. 


\section{Antigos Orifinais Fabiano Bossle, Vicente Molina Neto}

Neira e Nunes (2006) e Neira (2007). É possível identificar que há convergência entre esses autores em um sentido de tecer críticas a um modelo de metodologia de ensino em que estudantes não participam do processo de planejamento e construção das aulas, o que caracterizaria mais um modelo de educação bancária (FREIRE, 1987). Para a superação deste modelo de educação, Moreira (2004) enfatiza que a corresponsabilidade pela prática das atividades é uma possibilidade de ação nas aulas de educação física.

Pires e Neves (2001) convergem com a ideia de Moreira (2004) quando sublinham a defesa do princípio de uma cogestão em educação física. Embora o conceito de gestão tenha surgido recentemente no âmbito da educação e, mais especificamente, no da educação física, a ideia apresentada pelos autores não pode ser associada aos perversos princípios da administração científica, em que a cogestão assume um caráter que visa melhorar a produtividade e obter, de maneira consequente, aumento e especulação do lucro, mas sim, como uma necessidade de abrir para os estudantes a autoria sobre o próprio processo de ensino-aprendizagem, percebendo-se, assim, "com vez e voz" (PIRES; NEVES, 2001, p. 89).

Essas considerações sobre o reconhecimento à participação dos estudantes a partir do seu próprio universo cultural requerem, acima de tudo, a promoção de uma prática educativa compartilhada entre o professor de educação física e seus estudantes. Borges (2005) sublinha que os professores de educação física reconhecem um hiato existente entre sua formação inicial e a realidade de seu trabalho na sala de aula e na escola, porque estão diante das expectativas e necessidades de seus grupos de estudantes, compartilhando suas dificuldades com seus colegas de trabalho e são confrontados com programas, conteúdos e normas que precisam seguir. Essas limitações entre a prática educativa cotidiana e a formação já foram apresentados em Molina Neto (1996), Günther (2000) e Bossle (2003), porém o que talvez possa ser acrescentado é que há modelos de formação inicial que tem privilegiado algumas práticas educativas em detrimento da perspectiva de construção de trabalhos coletivos pelos professores de educação física nas escolas.

Movimento, Porto Alegre, v. 15, n. 03, p. 89-107, julho/setembro de 2009. 
Sublinhamos que, até aqui, os autores referenciados enfatizaram um processo de diálogo e interações coletivas entre estudantes e professores de educação física. Este pensamento é pautado pela codecisão nos níveis de planejamento, objetivos, conteúdos, avaliação do processo de ensino-aprendizagem e metodologias de ensino (CARDOSO, 1998), não tratando da possibilidade de trabalho coletivo entre ou dos professores de educação física.

Rangel-Betti (2001) sublinha que a construção de uma metodologia de ensino amparada na perspectiva reflexiva deve contemplar o entendimento de que a troca entre os pares é essencial. Entendemos que a autora se refere a uma das condições para adoção de uma prática reflexiva vendo a possibilidade de uma metodologia de ensino que implica, necessariamente, a reflexão sobre nossas ações, individuais e coletivas, como destacado por Rangel et al. (2005, p. 106) quando destacam a necessidade de "[...] trocar informações advindas destas reflexões com outros professores, tanto os da educação física, quanto das outras disciplinas".

Encontramos outra referência significativa sobre este aspecto da relação entre os professores de educação física em Krug e Silva (2004). Para estes autores, que realizaram uma investigação sobre o "bem" ou o "mal-estar" dos professores de educação física que atuam em escolas, foram identificados conflitos entre membros do mesmo coletivo docente que podem ser interpretados na condição de relações interpessoais ruins estabelecidas entre eles. Assim, estes autores preconizam uma postura colaborativa que permita refletir e investigar em equipe os problemas e projetar alternativas metodológicas conjuntas. Corroborando com esta ideia de Krug e Silva (2004), Bracht et al. (2003) afirmam:

[...] Uma das características importantes vinculadas à idéia do professor pesquisador e reflexivo é a busca do trabalho coletivo ou o entendimento da escola como um coletivo organicamente articulado, o que permitiria a valorização da autonomia dos docentes enquanto um agente educacional coletivo, aspecto ligado à democratização das relações intra-escolares (BRACHT et al., 2003, p. 121).

Movimento, Porto Alegre, v. 15, n. 03, p. 89-107, julho/setembro de 2009. 


\section{Antigos Orifinais Fabiano Bossle, Vicente Molina Neto}

Em uma pesquisa-ação realizada com professores de educação física atuantes em Escolas Públicas e Privadas do Espírito Santo, Bracht et al. (2003) identificaram dificuldades sobre o trabalho coletivo. Destacando a importância do trabalho coletivo, através da unanimidade na bibliografia que trata das inovações/mudanças educacionais, Bracht et al. (2003) expuseram sobre o grupo investigado a questão da desarticulação não somente dos professores de uma mesma disciplina, mas, também, com os de outras disciplinas e com o projeto pedagógico, indicando que quando não há um projeto pensado coletivamente, pode haver consequências sobre o trabalho coletivo e o individual (do professor de educação física e de outras disciplinas de maneira particular).

Em estudo sobre a construção do saber de dois professores de educação física, Borges (1998) também destaca aspectos significativos desta relação com professores de outras disciplinas sublinhados por Bracht et al. (2003). Borges (1998) interpretou que os professores participantes de seu estudo desenvolviam uma capacidade de interação com outros professores à medida que estabeleciam ligações mais estreitas baseadas na identificação com o projeto pedagógico e com os grupos de professores em que já havia articulações estabelecidas. A partir disso, podemos interpretar que o desenvolvimento de um maior ou menor grau de participação coletiva pode ocorrer, também, de acordo com a possibilidade de identificação de cada professor com o grupo e com o projeto político-pedagógico.

Boccardo (1993) destaca a evasão do sujeito em uma perspectiva de análise da autorreferência (discurso produzido pelo falante a respeito de si mesmo) no discurso de professor de educação física. Neste estudo, a autora analisa como os professores retiram-se do discurso através do uso de pronomes como nós, você, ou fazendo referência aos professores, às pessoas, à educação física, efetuando cada vez uma opção, quer pelo interlocutor, quer pelo grupo, onde se coloca na condição de anonimato, ao invés de assumir sua fala através de um eu. Ela sublinha, ainda, que é possível medir, assim, o nível de comprometimento pedagógico do professor através da análise da autorreferência, em termos percentuais, seja em termos de assumirse, através de sua linguagem, como um nós ou como um eu.

Movimento, Porto Alegre, v. 15, n. 03, p. 89-107, julho/setembro de 2009. 
Para Freire (2000) a ética do discurso é baseada na responsabilidade coletiva. Se assumirmos que a educação física é uma disciplina que tem como uma de suas características básicas a comunicação (linguagem verbal e corporal) através de vivências e experiências coletivas (GARIGLIO, 2001), podemos aproximar o pensamento de autores referenciados nessa seção como Hildebrandt-Stramann, Soares, Bracht e outros, com a "teoria da ação dialógica" de Freire (1987). Esta teoria está baseada no diálogo e interação entre as pessoas, sendo que pressupõe a colaboração, a união, a organização e tem como finalidade promover a conscientização coletiva. Desta forma, o entendimento da teoria de Freire (1987) como um ato de emancipação dos sujeitos na perspectiva de se perceber no mundo com os outros emerge como possibilidade de compreensão das leituras sobre trabalho coletivo na educação física escolar.

Pensamos que a emancipação, na perspectiva Freireana, é um conceito significativo para o entendimento sobre o trabalho coletivo dos professores de educação física. Fazemos essa afirmação reconhecendo que Paulo Freire não escreveu especificamente sobre educação física, mas a partir de uma leitura de mundo e de palavra como pressupostos de ser no mundo.

\section{ConsideraçõES FINAIS}

Atrevemo-nos a pensar, após a apresentação desta revisão bibliográfica, sobre o trabalho coletivo em algumas produções da área de conhecimento da educação física, que a formação crítica de alguns pesquisadores, nas décadas de 1980 e 1990, na Universidade Federal de Santa Maria/RS, foi fundamental para o começo de um pensar com o outro na educação física brasileira. Situamos a concepção de aulas abertas defendidas por Hildebrandt-Stramann e Laging (1986) como um movimento inicial que permite aos professores de educação física escolar uma releitura das próprias práticas educativas e, de maneira consequente, o início de uma reflexão e reconhecimento do "[....] desenvolvimento do potencial individual e social nas escolas" (SCHWAMBORN, 2004, p. 10). Retomamos essa ideia apresentada anteriormente sobre a influência e contribuição desses

Movimento, Porto Alegre, v. 15, n. 03, p. 89-107, julho/setembro de 2009. 
movimentos para a constituição de uma educação física crítica e transformadora, porque interpretamos que decorre daí uma demarcação espaço temporal do início de um perceber-se coletivamente na escola pela produção existente área de conhecimento da educação física brasileira.

Destacamos, ainda, que parece significativa a interpretação sobre uma "simbiose" entre trabalho coletivo na educação física e propostas político-pedagógicas fundamentadas na horizontalização das relações na escola. Concordamos com Neira (2004) quando enfatiza a necessidade de que o trabalho coletivo nas escolas seja resultado do encontro de vários projetos, como o sociopolítico, o educacional e os planos de ensino das diferentes disciplinas da matriz curricular.

Tardif e Lessard (2005) apontaram aspectos que podem facilitar ou não a existência de trabalhos coletivos nas escolas, e, entre eles, está a existência de Propostas Pedagógicas construídas de maneira coletiva. A implantação dos ciclos de formação e o conjunto de reestruturações que compõem o projeto da Rede de Ensino de Porto Alegre vêm promovendo inquietações significativas em diferentes áreas de conhecimento. Algumas investigações realizadas (GÜNTHER, 2006; WITTIZORECKI, 2001; BOSSLE, 2003; PEREIRA, 2004; SILVA, 2007; DIEHL, 2007) têm sublinhado a Proposta PolíticoPedagógica como possibilidade de construção coletiva nas escolas ao mesmo tempo em que apontam a necessidade do reconhecimento de uma proposta na qual cada professor de educação física se sinta sujeito (MOLINA; MOLINA NETO, 2004).

Sublinhamos ainda que, ao mesmo tempo em que identificamos a convergência entre trabalho coletivo e a elaboração de uma Proposta Político-Pedagógica, interpretamos que o mesmo não pode ser considerado "tábua de salvação" para as questões problemáticas a que estão submetidos os professores e as comunidades escolares. A interpretação das informações coletadas em mais de um ano de trabalho de campo em duas escolas da Rede Municipal de Ensino Porto Alegre, através da realização de uma autoetnografia ${ }^{3}$ e de uma etnografia,

Movimento, Porto Alegre, v. 15, n. 03, p. 89-107, julho/setembro de 2009. 
contempla e complementa esta perspectiva de aproximação entre o referencial teórico que apresentamos neste texto e nossas interpretações sobre o trabalho coletivo dos professores de educação física configurado em uma cultura docente singular.

De maneira complementar, foi possível aproximar a análise das leituras apresentadas neste texto com as informações coletadas no trabalho de campo realizado, em que foi possível compreender os limites e as possibilidades de realização de trabalho docente coletivo a partir das representações singulares dos professores de educação física de duas escolas da Rede de Ensino de Porto Alegre. Sobretudo, é possível pensar que o não reconhecimento de alguns aspectos que limitam a construção do trabalho coletivo por este coletivo docente poder estar interligado com a própria identidade da educação física na escola e nos desdobramentos desta com as outras áreas de conhecimento na escola.

\begin{abstract}
Reading to thing the collective work of the teachers of physical education in the education network hall of Porto Alegre.

Abstract: This article is a bibliographical revision on the collective work in the physical school Brazilian education. The objective is to revise in the productions of the Area of Knowledge of the Physical Education and Sciences of the Sport the approaches on the collective work. There were analysed the annals of three congresses of the area of knowledge of the physical education and sciences of the sport in the years of 2006 and 2007, books and theories and dissertations. It was possible to identify the context in which it surfaces the discussions on collective work in the physical school Brazilian education and the space what this theme has been occupying in the production of this Area of Knowledge in the days of today, as well as, a "symbiosis" between collective work in the education physical and when pedagogic-politician was proposed based on the horizontalização of the relations on the school. Keywords: Review literature as topic. Faculty. Physical education school.
\end{abstract}

\footnotetext{
${ }^{3}$ De acordo com Berger e Ellis (2007), a autoetnografia pode ser entendida como uma narrativa de estilo autobiográfico que conecta uma dimensão pessoal do próprio pesquisador com suas experiências culturais.

Movimento, Porto Alegre, v. 15, n. 03, p. 89-107, julho/setembro de 2009.
} 


\begin{abstract}
Lecturas para (re)pensar el trabajo colectivo de los profesores de educación fisica en la Red de Ensenanza del Municipio de Porto Alegre.

Resumen: Este artículo es una revisión de la literatura sobre el trabajo colectivo en la escuela brasileña de educación física. El objetivo es revisar la producción del Área de Conocimiento de la Educación Física y Deporte Ciencias de los enfoques sobre el trabajo colectivo. Se analizaron las actuaciones de tres conferencias en el área de conocimiento de la educación física y el deporte ciencia en los años 2006 y 2007, los libros y tesis y disertaciones. Es posible identificar en el que surgen los debates sobre el trabajo colectivo en la educación física escolar y el espacio brasileño que este tema ha ocupado en este ámbito de producción de conocimiento hoy en día, así como una "simbiosis" entre el trabajo colectivo en la educación física y el políticas y propuestas pedagógicas basadas en las relaciones "horizontalisation" en la escuela.

Palavras clave: Literatura de revisión como asunto. Docentes. Educación física escolar.
\end{abstract}

\title{
REFERÊNCIAS
}

BERGER, L; ELLIS, C. Composing Autoethnographic Stories. In:ANGROSINO, M. V. Doing Cultural Anthropology: projects for ethnographic data collection. 2. ed. Los Angeles: Waveland Press/University of Southern California, 2007. p. 151-166.

BOCCARDO, L. M. Comprometimento Pedagógico no Discurso Docente. In: VOTRE, S. (Org.) Ensino e Avaliação em Educação Física. São Paulo: IBRASA, 1993. p. 83-99.

BORGES, C. M. F. A Formação dos Docentes de Educação Física e seus Saberes Profissionais. In: BORGES, C. M. F.; DESBIENS, J. F. (Org.) Saber, Formar e Intervir para Uma Educação Física em Mudança. Campinas, SP: Autores Associados, p. 157 - 190. 2005.

BORGES, C. M. F. O Professor de Educação Física e a Construção do Saber. Campinas, S.P: Papirus, 1998.

BOSSLE, F. "O Eu do Nós": o professor de educação física e a construção do trabalho coletivo na Rede Municipal de Ensino de Porto Alegre. Porto Alegre: 2008. Tese (Doutorado em Ciências do Movimento Humano), Escola de Educação Física da Universidade Federal do Rio Grande Sul, Porto Alegre, 2008.

BOSSLE, F. Planejamento de Ensino dos Professores de Educação Física do $2^{\circ}$ e $3^{\circ}$ Ciclos da Rede Municipal de Ensino de Porto Alegre: um estudo do tipo etnográfico em quatro escolas desta Rede de Ensino. 2003. Dissertação

Movimento, Porto Alegre, v. 15, n. 03, p. 89-107, julho/setembro de 2009. 
(Mestrado em Ciências do Movimento Humano). Escola de Educação Física da Universidade Federal do Rio Grande do Sul, Porto Alegre, 2003.

BRACHT, V. Educação Física e Aprendizagem Social. Porto Alegre: Magister, 1992.

BRACHT, V. et al. Pesquisa em Ação: Educação Física na escola. ljuí: UNIJUí, 2003. (Coleção Educação Física)

CARDOSO, C. L. Concepção de Aulas Abertas. In: KUNZ, E. (org.) Didática da Educação Física 1. ljuí: UNIJUÍ, 1998. p. 121-158. (Coleção Educação Física).

CASTELLANI FILHO, L. Educação Física no Brasil: a história que não se conta. 4. ed. Campinas, SP: Papirus, 1994.

CORREAA, I. L. S.; MORO, R. L. Educação Física Escolar: reflexão e ação curricular. ljuí: UNIJUÍ, 2004.

DIEHL, V. R. O. O Impacto das Mudanças Sociais na Ação Pedagógica dos Docentes de Educação Física da Rede Municipal de Porto Alegre: implantação e implementação do Projeto Escola Cidadã. 2007. Dissertação (Mestrado em Ciências do Movimento Humano). Escola de Educação Física da Universidade Federal do Rio Grande do Sul, Porto Alegre, 2007.

DIEHL, V. R. O.; GÜNTHER, M. C. C.; LOURENÇO, B. O Impacto das Mudanças Sociais na Ação Pedagógica dos Docentes de Educação Física da Rede Municipal de Porto Alegre: implantação e implementação do Projeto Escola Cidadã. In: CONGRESSO BRASILEIRO DE CIÊNCIAS DO ESPORTE E 2. CONGRESSO INTERNACIONAL DE CIÊNCIAS DO ESPORTE, 15. Anais... Recife: Colégio Brasileiro de Ciências do Esporte, 2007.

FIGUEIREDO, Z. C. C. e Colaboradoras. Educação Física, Ser Professor e Profissão Docente em Questão... In: CONGRESSO BRASILEIRO DE CIÊNCIAS DO ESPORTE E 2. CONGRESSO INTERNACIONAL DE CIÊNCIAS DO ESPORTE, 15. Anais... Recife: Colégio Brasileiro de Ciências do Esporte, 2007.

FREIRE, P. Pedagogia da Indignação: cartas pedagógicas e outros escritos. São Paulo: Editora UNESP, 2000.

FREIRE, P. Pedagogia do Oprimido. 17. ed. Rio de Janeiro: Paz e Terra, 1987.

GARIGLIO, J. A. Proposta de Ensino de Educação Física para uma escola profissionalizante: uma experiência no CEFET-MG. In: CAPARROZ, F. E. (Org.) Educação Física Escolar. Vitória: Proteoria, 2001, p. 29-65.

GRUPO DE TRABALHO PEDAGÓGICO UFPE/UFSM. Visão Didática da Educação Física: análises críticas e exemplos práticos de aulas. Rio de Janeiro: Ao Livro Técnico, 1991.

GÜNTHER, M. C. C. A Prática Pedagógica dos Professores de Educação Física e o Currículo Organizado por Ciclos: um estudo na Rede Municipal de

Movimento, Porto Alegre, v. 15, n. 03, p. 89-107, julho/setembro de 2009. 


\section{Antigos Originais Fabiano Bossle, Vicente Molina Neto}

Ensino de Porto Alegre. 2006. Tese (Doutorado em Ciências do Movimento Humano). Escola de Educação Física da Universidade Federal do Rio Grande do Sul, Porto Alegre, 2006.

GÜNTHER, M. C. C. Formação Permanente de Professores de Educação Física na Rede Municipal de Ensino de Porto Alegre no Período de 1989 a 1999: um estudo a partir de quatro escolas da Rede. 2000. Dissertação (Mestrado em Ciências do Movimento Humano). Escola de Educação Física da Universidade Federal do Rio Grande do Sul, Porto Alegre, 2000.

HILDEBRANDT-STRAMANN, R.; LAGING, R. Textos Pedagógicos sobre o Ensino da Educação Física. ljuí: UNIJUÍ, 2001. (Coleção Educação Física).

HILDEBRANDT-STRAMANN, R.; LAGING, R. Concepções Abertas no Ensino de Educação Física. Rio de Janeiro: Ao Livro Técnico, 1986.

KRUG, H. N.; SILVA, M. S. Os Sentimentos de Bem ou Mal-Estar Docente dos Professores de Educação Física Escolar no Ensino Fundamental de Santa Maria (RS): um estudo fenomenológico. Biomotriz, Revista Científica da Faculdade de Educação Física da Universidade de Cruz Alta, Cruz Alta, n. 2, p. 38-46. nov/dez, 2004a.

KUNZ, E. Transformação Didático-Pedagógica do Esporte. ljuí: UNIJUÍ, 1994.

KUNZ, E. Educação Física: ensino e mudanças. ljuí: UNIJUÍ, 1991.

LISTON, D. P.; ZEICHNER, K. M. Formación del Profesorado y Condiciones Sociales de la Escolarización. Madrid: Morata, 1997.

MERIDA, F. Processo de Construção de um Planejamento Anual de Educação Física em Linha do Tempo. In: CONGRESSO CIÊNCIAS DO DESPORTO E EDUCACCÃO FíSICADOS PAIISES DE LÍNGUAPORTUGUESA, 11. São Paulo: Revista Brasileira de Educação Física e Esporte, set. 2006, v. 20, supl. n. 5, p. 375.

MOLINA NETO, V. La Cultura Docente Del Profesorado de Educación Física de Las Escuelas Públicas de Porto Alegre. 1996. Tese (Doutorado). Barcelona: Universitat de Barcelona. Departament de Didáctica i Organizació Educativa. Divisió de Ciences de l'Educació, 1996.

MOLINA NETO, V. ; MOLINA, R. K. O Que os Professores de Educação Física têm a Dizer sobre os Ciclos de Formação. In: MOLL, J. Ciclos na Escola, Tempos na Vida: criando possibilidades. Porto Alegre: ARTMED, 2004. p. 235 - 247.

MOLINA NETO, V. A Prática do Esporte nas Escolas de $1^{\circ}$ e $2^{\circ}$ Graus. Porto Alegre: Ed. Universidade da UFRGS, 1993.

MOREIRA, E. C. Educação Física no Ensino Fundamental: a (re)construção dos significados. In: MOREIRA, E. C. (Org). Educação Física Escolar: desafios e propostas. Jundiaí, Fontoura, 2004. p. $15-34$.

NEIRA, M. G. ; NUNES, M. L. F . Ensino de Educação Física. São Paulo: Thomson Learning, 2007. (Coleção Ideias em Ação).

Movimento, Porto Alegre, v. 15, n. 03, p. 89-107, julho/setembro de 2009. 
NEIRA, M. G. ; NUNES, M. L. F. Pedagogia da Cultura Corporal: crítica e alternativas. São Paulo: Phorte, 2006.

NEIRA, M. G. Por Dentro da Sala de Aula: conversando sobre a prática. São Paulo: Phorte, 2004.

OLIVEIRA, A. A. B.; OLIVEIRA, E. R. N. Os Conteúdos da Educação Física Escolar e a Relação destes com as Demais Áreas de Conhecimento do Processo Educacional. In: CONGRESSO CIÊNCIAS DO DESPORTO E EDUCAÇÃO FÍSICADOS PAÍSES DE LÍNGUA PORTUGUESA, 11. 2006. Revista Brasileira de Educação Física e Esporte, São Paulo, set. 2006. v. 20, supl. n. 5, p. 371.

PALAFOX, G. H. M. Planejamento Coletivo do Trabalho Pedagógico da Educação Física - PCTP/EF como Sistemática de Formação Continuada de Professores: a experiência de Uberlândia. Movimento. Porto Alegre, v. 10, n. 1, p. 113-131, jan./ abr. 2004.

PALAFOX, G. H. M. Principais Diretrizes do Planejamento Coletivo do Trabalho Pedagógico - PCTP: a experiência de Uberlândia. In: PALAFOX, G. H. M. (Org.) Planejamento Coletivo do Trabalho Pedagógico - PCTP: a experiência de Uberlândia. 2. ed. Uberlândia: Casa do livro; Linograf, 2002. p. 25-32.

PEDROZA, R. S.; RODRIGUES, A. T. Ciclos de Desenvolvimento Humano e Avaliação em Educação Física: a desconstrução anunciada. In: CONGRESSO BRASILEIRO DE CIÊNCIAS DO ESPORTE,15. 2007. Anais... Recife: Colégio Brasileiro de Ciências do Esporte, 2007.

PEREIRA, R. R. A Interdisciplinaridade na Ação Pedagógica do Professor de Educação Física da Rede Municipal de Ensino de Porto Alegre. 2004. Dissertação (Mestrado em Ciências do Movimento Humano). Escola de Educação Física da Universidade Federal do Rio Grande do Sul, Porto Alegre, 2004.

PIRES, G. D. L.; NEVES, A. O Trato com o Conhecimento Esporte na Formação em Educação Física: possibilidades para sua transformação didático-metodológica. In: KUNZ, E. (Org.) Didática da Educação Física 2. Ijuí: UNIJUÍ, p. 53-97, 2001. (Coleção Educação Física).

PORTO ALEGRE. Secretaria Municipal De Educação. Ciclos de Formação, Proposta Político-Pedagógica da Escola Cidadã. Cadernos Pedagógicos, n. 9, abr. 1999.

RANGEL, I. C. A. et al. O Ensino Reflexivo como Perspectiva Metodológica. In: DARIDO, S. C.; RANGEL, I. C. A. Educação Física na Escola: implicações para a prática pedagógica. Rio de Janeiro: Guanabara Koogan, 2005. p. 103-121. (Coleção Educação Física no Ensino Superior).

RANGEL-BETTI, I. C. Educação Física e o Ensino Médio: analisando um processo de aprendizagem profissional. Motriz. Rio Claro,S.P:, v. 7, n. 1, p. 22-29, 2001.

SANCHOTENE, M. U. A Relação entre as Experiências Vividas pelos Professores de Educação Física e sua Prática Pedagógica: um estudo de caso. 2007. $143 f$. Dissertação (Mestrado em Ciências do Movimento Humano). Escola de Educação Física da Universidade Federal do Rio Grande do Sul, Porto Alegre, 2007.

Movimento, Porto Alegre, v. 15, n. 03, p. 89-107, julho/setembro de 2009. 


\section{Artifor Orifimais Fabiano Bossle, Vicente Molina Neto}

SANTINI, J. A Síndrome do Esgotamento Profissional: o "abandono" da carreira docente dos professores de Educação Física da Rede Municipal de Ensino de Porto Alegre. 2004. Dissertação (Mestrado em Ciências do Movimento Humano). Escola de Educação Física da Universidade Federal do Rio Grande do Sul, Porto Alegre, 2004.

SANTOS, M. V. O Estudante na Cultura Estudantil e na Educação Física Escolar. 2007. Dissertação (Mestrado em Ciências do Movimento Humano). Escola de Educação Física da Universidade Federal do Rio Grande do Sul, Porto Alegre, 2007.

SCHMIDT, K. C. et al. O Abandono da Regência de Classe de Professores de Educação Física da Rede Estadual de Ensino de Santa Catarina: um estudo de caso. In: CONGRESSO CIÊNCIAS DO DESPORTO E EDUCAÇÃO FÍSICADOS PAíSES DE LÍNGUA PORTUGUESA, 11. São Paulo. Revista Brasileira de Educação Física e Esporte, São Paulo, set. 2006. v. 20, supl. n. 5, p. 369.

SCHWAMBORN, F. Apresentação. In: KUNZ, E.; HILDEBRANDT-STRAMANN, R. (Org.) Intercâmbios Científicos Internacionais em Educação Física e Esportes. Ijuí: UNIJUÍ, p. 9 - 13, 2004.

SILVA, L. O.; MOLINA NETO, V. Identização das Docentes de Educação Física da Rede Municipal de Ensino de Porto Alegre. In: CONGRESSO CIÊNCIAS DO DESPORTO E EDUCAÇÃO FÍSICA DOS PAÍSES DE LÍNGUA PORTUGUESA, 11. São Paulo. Revista Brasileira de Educação Física e Esporte, São Paulo, set. 2006. v. 20, supl. n. 5, p. 351.

SILVA, L. O.; MOLINA NETO, V.. Um Estudo de Caso com Mulheres Professoras sobre o Processo de Identização Docente em Educação Física na Rede Municipal de Ensino de Porto Alegre. 2007. Dissertação (Mestrado em Ciências do Movimento Humano). Escola de Educação Física da Universidade Federal do Rio Grande do Sul, Porto Alegre, 2007.

SILVA, L. O.; MOLINA NETO, V.; SANCHOTENE, M. U. Um Estudo de Caso com Mulheres Professoras sobre o Processo de Identização Docente em Educação Física na Rede Municipal de Ensino de Porto Alegre. In: CONGRESSO BRASILEIRO DE CIÊNCIAS DO ESPORTE, 15. Anais ... Recife: Colégio Brasileiro de Ciências do Esporte, 2007.

SOARES, Carmem L. et. al. Metodologia de Ensino de Educação Física. São Paulo: Cortez, 1992. (Série Formação do Professor).

TAFFAREL, C. N. Z. A Formação do Profissional da Educação: o processo de trabalho pedagógico e o trato com o conhecimento no curso de Educação Física. 1993. Tese (Doutorado em Educação). Universidade Estadual de Campinas. Faculdade de Educação, Programa de Pós-Graduação em Educação, 1993.

TARDIF, M.; LESSARD, C. O Trabalho Docente: elementos para uma teoria da docência como profissão de interações humanas. Petrópolis, RJ: Vozes, 2005.

Movimento, Porto Alegre, v. 15, n. 03, p. 89-107, julho/setembro de 2009. 
TERRA, D. V. La Construcción del Saber Docente de los Profesores de Educación Física: los campos de vivencia. 2003. (Tese de Doutorado). Barcelona: Universitat de Barcelona. Departament de Dadàctica i Organització Educativa, 2003.

TERRA, D. V. Orientação do Trabalho Colaborativo na Construção do Saber Docente: a perspectiva do planejamento coletivo do trabalho pedagógico. Movimento, Porto Alegre, v. 10, n. 1, p. 157-179, jan./abril, 2004.

WITTIZORECKI, E. S. O Trabalho Docente dos Professores de Educação Física na Rede Municipal de Ensino de Porto Alegre: um estudo nas escolas do Morro da Cruz. 2001. Dissertação (Mestrado em Ciências do Movimento Humano). Escola de Educação Física da Universidade Federal do Rio Grande do Sul, Porto Alegre, 2001.

Recebido em: 19.11.2008

Aprovado em: 31.03.2009

Movimento, Porto Alegre, v. 15, n. 03, p. 89-107, julho/setembro de 2009. 